\section{Анализ себестоимости обезличенного кубометра круглых лесоматериалов}

\author{
В. И. Марков ${ }^{1}$ \\ А. А. Фролова \\ P. С. Шашкина
}

Петрозаводский государственный университет

В условиях формирования рыночньх отношений изучение себестоимости представляет особый интерес с точки зрения ее роли и места в системе ценообразования и в финансовом механизме вообще, поскольку она стала полнее осуществлять свои функции и как элемент управления.

Ключевые слова: себестоимость, структура, затраты, калькулячия, анализ, кубометр, древесина, лесные таксы, цена.

\section{СОДЕРЖАНИЕ}

В современньх условиях уровень себестоимости позволяет дать экономическую оценку деятельности предприятия и его конкурентноспособности. .

В себестоимости находит отражение использование как живого, так и прошлого труда в едином денежном измерителе.

Расчеты себестоимости на предприятиях лесной промышленности регламентируются следующими нормативными документами:

1. Инструкции по планированию, учету и калькулированию себестоимости продукции лесоэксплуатации;

2. Положение о составе затрат, включаемьх в себестоимость.

Однако действующая методика планирования и учета затрат на заготовку обезличенного кубометра кругльх лесоматериалов соблюдается не на всех предприятиях, поэтому затраты на одинаковые виды работ на разньх предприятиях отражаются в разных статьях затрат калькуляции. На некоторьх предприятиях отсутствуют расчеты плановой себестоимости, а иногда и фактической, ограничиваясь расчетом себестоимости товарной продукции.

На основе материалов фактических калькуляций проведен предварительный анализ динамики и структуры себестоимости обезличенного кубометра древесины по отдельньм предприятиям Карелии. Выявле-

\footnotetext{
${ }^{1}$ Авторы - соответственно зав. кафедрой промыиленного транспорта и геодезии, дочент и $\mathrm{cm}$. преподаватель кафедры отраслевых экономик

(ㄱ В. И. Марков, А. А. Фролова, Р. С. Шашкина, 1999
}

на четкая тенденция роста затрат на лесопродукцию по всем предприятиям.

Увеличение затрат на производство кругльгх лесоматериалов обусловлено как объективными, так и субъективными причинами.

В последние годы наблюдается резкое увеличение лесньх такс, цен на новую технику, запасные части и материалы для ремонта, на топливо и смазочные материалы; повышение тарифных ставок работников отрасли. Проведена переоценка основных фондов в 1992, 1994, 1995 годах. Кроме того, на предприятиях осуществляется переход на сортиментную вывозку. А переход на новую технику и технологию в первые годы (начальный период) освоения характеризуется более высокими издержками производства. Это связано с тем, что в начальный период технология и организация производственной деятельности еще полностью не отлажены, недостаточна квалификация работников, а значит и низка производительность труда (следовательно, на каждый кубометр кругльх лесоматериалов увеличивается заработная плата). Затраты на производство увеличиваются и за счет дополнительных капиталовложений, связанных с приобретением новой техники и обучением работников для работы на ней или наймом новьг работников.

В качестве субъективных причин, приведших к увеличению затрат на производство кругльг лесоматериалов, можно отметить следующие:

1. Снижение годовой выработки на списочную машину из-за недоиспользования фонда времени (за счет уменьшения количества отработанных машино-смен, коэффициентов сменности и использования исправньх машин), даже при уменьшении среднего расстояния вывозки и увеличении сменной производительности.

2. Недовыполнение норм выработки на лесосечных работах.

3. Неритмичная работа по фазам технологического процесса. Хроническое отставание фактической заготовки леса в течение года от планового задания является основной причиной невыполнения плана по вывозке и соответственно по раскряжевке.

4. Недостаточное использование календарного фонда времени.

5. Несоблюдение нормативного соотношения между приростом средней заработной платы и приростом производительности труда.

Вышеперечисленные факторы влияют на увеличение расходов практически всех статей затрат себестоимости кругльх лесоматериалов. 
Структура производственной себестоимости по годам (рис. 1) характеризуется небольшими колебаниями как в сторону уменьшения, так и увеличения. Но по некоторым статьям затрат наблюдается четкая тенденция роста - это расходы по содержанию и эксплуатации оборудования (включая расходы по содержанию лесовозньх работ), общехозяйственные расходы.

Затраты по статье "Общехозяйственные расходы" имеют также четкую тенденцию роста.

При анализе себестоимости $1 \mathrm{~m}^{3}$ круглых лесоматериалов на отдельных предприятиях Карелии, Архангельской, Вологодской и Ленинтрадской областей (графические материалы на рис. 2) видно, что важнейшей особенностью, характерной для предприятий Карелии, является высокий уровень попенной платы.

В 1995 году он составил 13, 14 и 13\%, в то время как на предприятиях соседних регионов 8 и $4 \%$. Конечно же, сравнение по этой статье без учета природноклиматических и географических условий вряд ли правомочно, однако наличие такой информации говорит о необходимости более серьезного подхода к изучению этого вопроса.
В 1994 году доля зарплаты с отчислениями на предприятиях Карелии оказались ниже не только по сравнению с предприятиями Архангельской и Вологодской области, но даже и с Ленинградской. В 1995 году положение по зарплате в рассматриваемых регионах несколько выправилось.

Что же касается расходов по содержанию и эксплуатации оборудования, то они по кругу рассматриваемых предприятий довольно близки, а за 1995 году эти расходы составили больше 20 тыс. руб. на $1 \mathrm{~m}^{3}$, что в 1,5 раза меньше, чем на предприятиях Архангельской области.

Для лесозаготовительньх предприятий Карелии, как уже отмечалось выше, характерным является довольно большой удельный вес общехозяйственньх и внепроизводственных расходов. Анализ сложившегося положения требует более детального изучения информации по группе этих затрат. 


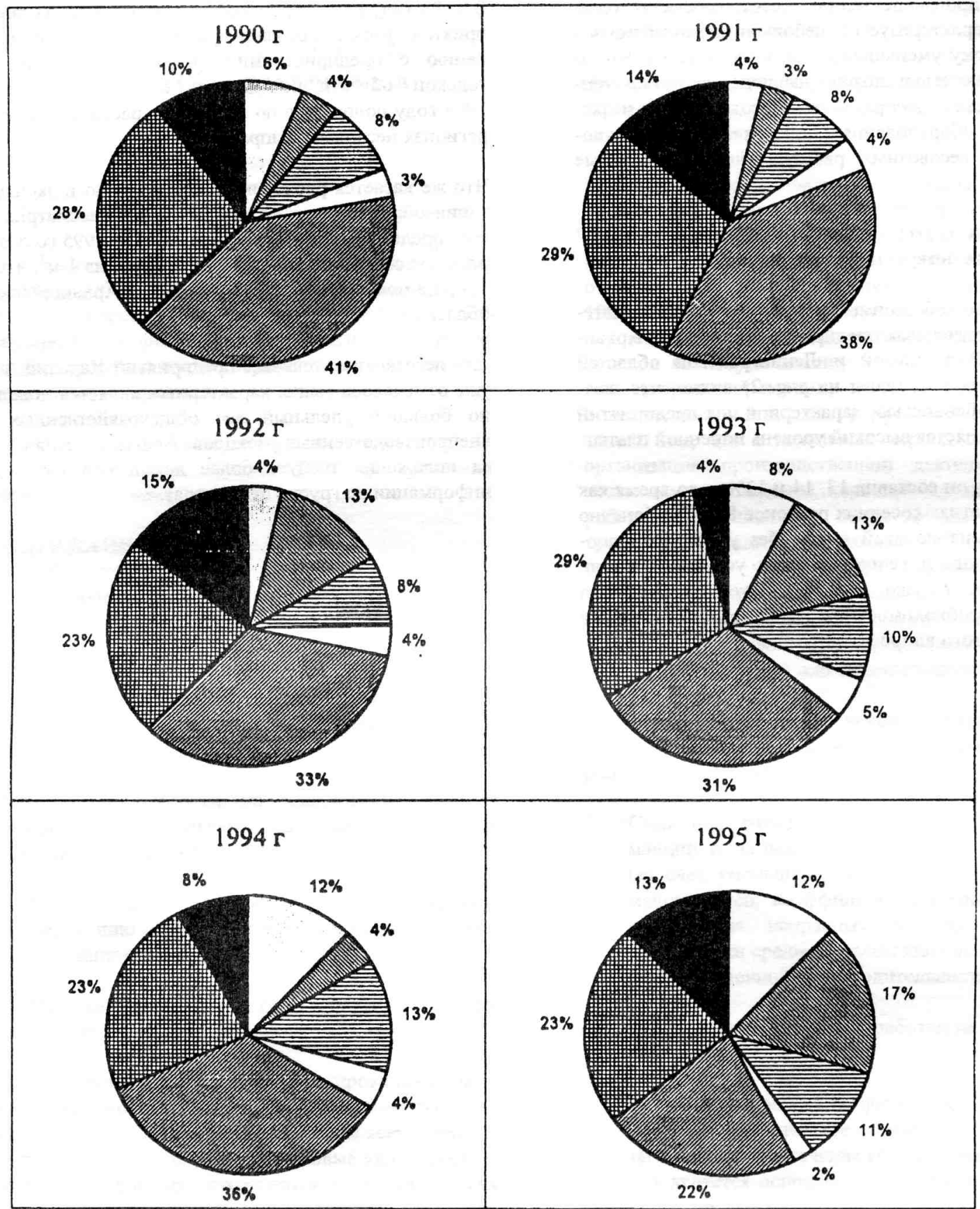

Прочие производственные расходы; Внепроизводственные расходы;

Цеховые расходы;

Общехозяйственные расходы;

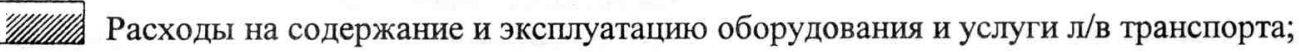

Зарплата с отчислениями;

Попенная плата.

Рис. 1. Структура фактической себестоимости $1 \mathrm{M}^{3}$ круглых лесоматериалов в леспромхозе $1 \mathrm{~K}$ 


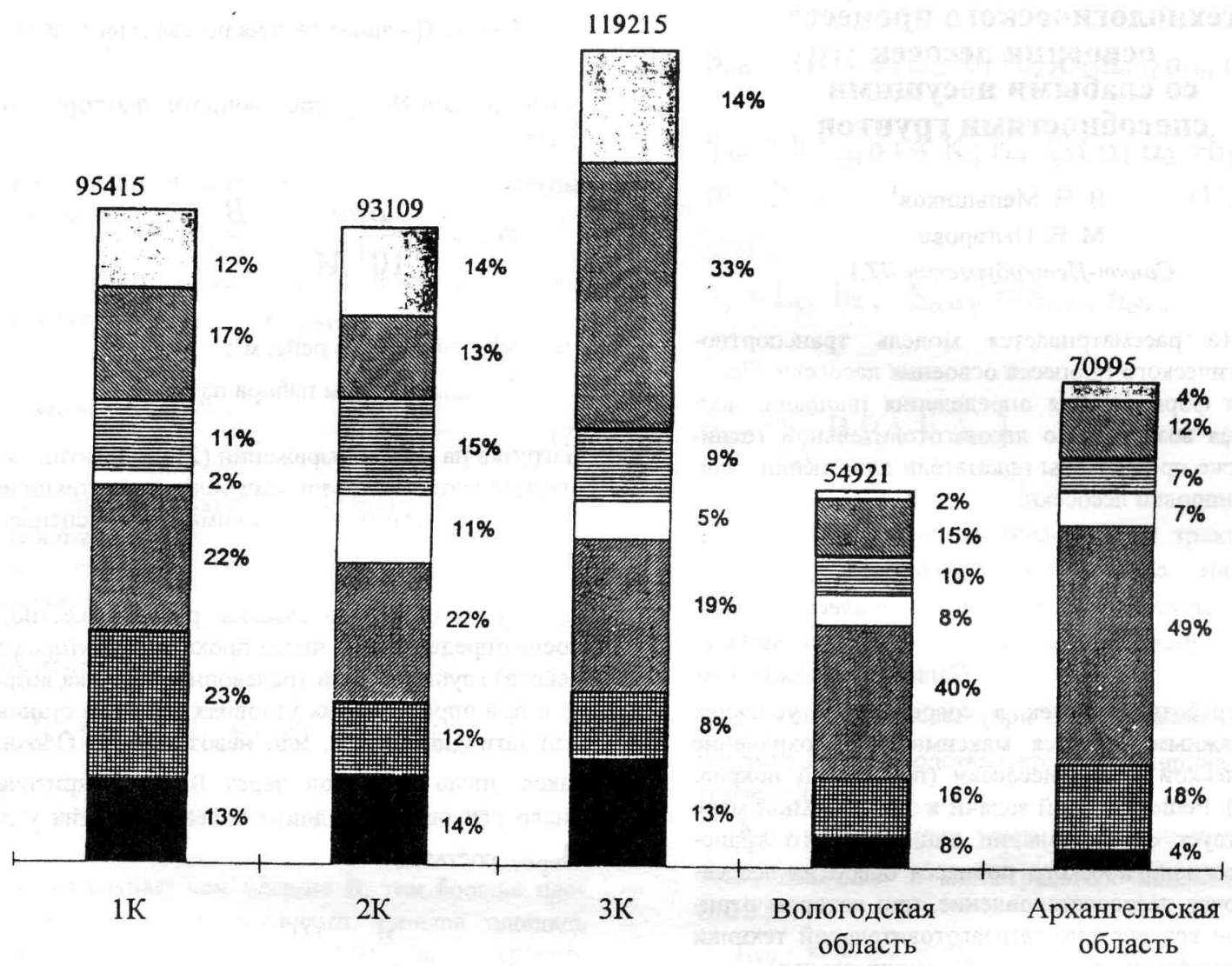

口 Внепроизводственные расходы;

圈 Прочие производственные расходы;

目 Общехозяйственные расходы;

$\square$ Цеховые расходы;

Р Расходы на содержание и эксплуатацию оборудования и л/в транспорта;

田 Зарплата с отчислениями;

Попенная плата.

Рис. 2. Фактическая себестоимость 1 м $^{3}$ круглых лесоматериалов в 1995 году (тыс. руб.) 